\title{
The use of Macintosh 24-bit color and animation programs in undergraduate research and visual perception courses
}

\author{
GLENN E. MEYER, DANIEL J. ROCHELEAU, JAMES MCMULLEN, and BRENT E. RITTER \\ Lewis and Clark College, Portland, Oregon
}

\begin{abstract}
Computer displays are becoming a preferred method of stimulus presentation in visual research. Yet because graduate research is for the most part performed with dedicated systems and software, many phenomena are inaccessible to undergraduates except as illustrations or descriptions in textbooks. We have found that a laboratory with three or four commercial programs can duplicate complex phenomena well enough to be useful in teaching and research, without any need for undergraduates to attain sophisticated programming skills.
\end{abstract}

Computer-generated displays are becoming one of the preferred methods of stimulation in visual research. The necessity of quickly and simultaneously controlling motion, color, and/or luminance would preclude the easy use of the whirling disks, lens, filters, and colored papers of the past. In fact, many of the popular phenomena of today's scholars would be quite difficult to produce with optics and electromechanical devices. The time to set up such devices and calibrate them does not make for easy classroom or undergraduate student use.

We surveyed the 1989 volumes of some of the most important journals in visual perception and science (Perception, Perception \& Psychophysics, Vision Research, Spatial Vision), in order to determine what computerdriven displays are being used. Of course, there is a lag time in publication, and the world of equipment is ever changing; but we were surprised by our results. There is a great diversity among platforms, and no standard seems to have emerged (see Appendix A). Analysis of the visual literature suggests that graduate-level research is for the most part performed on dedicated systems that vary widely in sophistication. Machinery ranges from the Apple II to Sun workstations and relatively high-end image processors. It seems also to be the case that the displays are specifically programmed for the task at hand. Methods sections make little mention of actual programming, but there are passing references to LISP or BASIC.

There is little mention of commercial graphics and presentation packages. The computer magazines are full of descriptions of the graphics abilities of Amigas, 80386 PC clones, and Mac II families of computers that offer 8- to 32-bit color with animation capacities. It is perhaps

This project was supported by a grant from the M. J. Murdock Charitable Trust. We wish to thank Michael Flower for his help in supplying funding. A videotape of some of the animations is available from the first author, as are copies of the MacroMind Director files. Reprints are available from Glenn E. Meyer, Department of Psychology, Lewis and Clark College, Portland, OR 97219. the case that research based on these platforms is now in the pipeline. We have seen some evidence of this presented at conferences such as the annual meeting of the Psychonomic Society or the Association for Research in Vision and Ophthalmology, but it is just beginning. We are also aware of Amiga, PC, and Mac IIcx or ci labs being established (Anstis \& Paradiso, 1989).

If most visual displays are being generated on a variety of platforms with task-specific software, there is a problem for undergraduate students at various institutions. Even if they are interested in research, they usually do not have the time to learn a specific platform and program an experiment unless they are unusually dedicated or they have started learning sophisticated programming skills fairly early in their career. In the Macintosh environment, demonstration packages and Hypercard stacks such as Contour (subjective contours; Dougherty, 1990), MacLaboratory (Chute \& Daniel, 1988), and the Active Eye (Mills \& Schiff, 1988) do exist. Programs with research capabilities are becoming available, such as Enns, Ochs, and Rensink's (1990) VSearch (for visual search) or Stork and Rocca's (1989) program to generate stereograms. However, these work in limited domains and full color and brightness control may not be available. Thus, many sophisticated and "cutting-edge" phenomena are not available to students in a form that is easily manipulated. The undergraduates must accept illustrations or descriptions in a text. And the existing software is not particularly oriented for easy exploration of visual phenomena, for modifying the displays, or for encouraging spontaneous creativity in the novice despite the software's excellence for the researcher.

It would seem that given a chance to interact with the phenomena of visual perception, students might understand the concepts better. Sometimes, to read descriptions of neurons and sine waves may be less than motivating. Can one really claim that seeing a gray square over a set of varying white to black squares has inspired one to study lateral inhibition and contrast effects? There have been 
suggestions that animated displays can be useful tools in learning (Rieber, Boyce, \& Assad 1990). We have found that animating that old chestnut of a contrast display can really be quite effective.

\section{Lewis and Clark Environment}

Macintosh computers are prevalent at Lewis and Clark College. All entering students take a core writing course in which Macintosh SE computers and Microsoft Word are used. The psychology major includes a methodology course in which Macintoshes are used for statistical analyses, table and graph preparation (Statview), and learning APA format and writing style. Thus, the students have a fair familiarity with the Macintosh graphic user interface and with Macintosh-style software. In this paper, we report our attempts to let students interact in a participatory and creative manner with visual phenomena. We also document a wide range of effects and demonstrations that can be produced with reasonable effort on the part of faculty and students.

We have found that a laboratory with three or four commonly available commercial programs can duplicate complex phenomena well enough to be useful in teaching and research without the need for undergraduates to attain sophisticated programming skills. It seemed to us that we needed to have reasonable control of color, brightness, form, and time. Our platforms of choice were the Macintosh II family (that was what we were able to talk the administration into buying for us, given the schools' penchant for Apple products and the positive transfer from the core program). Machines were equipped with either Macintosh 8-bit video boards or RasterOps 264 24-bit graphics boards (see Appendix B).

After reading magazine reviews and talking to colleagues and companies, we decided to standardize our lab with the set of programs described in Appendix C. MacroMind Director is a powerful animation program, the successor to Videoworks. It has 8- to 24-bit color depth and powerful paint capacities. The package also includes presentation organizing abilities and a HyperCard-like language. Canvas is a draw-and-paint program, also with 8to 24-bit color capacities. Both will run on the Macintosh II family of computers with 8-bit color video boards. Super 3-D is a three-dimensional animation-and-draw program. Pixel Paint Professional is a powerful paint program with 24-bit color capacities. However, it will only run on machines with a 24-bit color video board installed (such as the RasterOps 264 board that we used). MacVision is a combination software and hardware package that allows a video camera to scan objects and save them in 8-bit gray scale across a variety of graphic formats. All these programs can easily interact with each other. MacroMind Director can capture art from any of the other programs, and Pixel Paint Professional can open almost any standard graphics format. Super 3-D can send a stream of frames to MacroMind Director for further enhancement and control of the animation.
Draw programs have the advantage of defining elements of the picture as separate entities. They are said to be "object oriented." A circle has attributes such as size, color, border, texture, and so forth. If it is drawn over, the occluded part is not "gone." The object can be easily duplicated. In paint programs, once applied to the field, the pictorial element has no independent existence. If one puts something else over the element, the occluded part is gone. One can duplicate areas on the screen but not an object per se. There are some protection or masking schemes in paint programs, but they are limited.

The issue of 8- versus 24-bit capabilities is of some importance. The first issue is the ability to produce or present images with some degree of photorealism. An 8-bit program will give 256 available colors or gray scale levels. A 24-bit program will provide more than $16,000,000$. A human face will look reasonable with 256 gray scale levels. However, a color picture of a red apple shows unacceptable banding with only a 256-color palette, owing to the inability to map the continuous changes in brightness, hue, and saturation found with real stimuli at a change level below that of our resolution limits. In a similar vein, 24-bit programs have superior capacity for antialiasing in color and gray scale. This is a problem with graphics platforms such as the early Amigas ( Wenderoth, 1990). Also, the graphics tools with the 24-bit version of Pixel Paint Professional are much improved, compared to those with the earlier 8-bit versions.

This is not to say that 8-bit programs have severe handicaps. At the 8-bit level, one can choose between a wide variety of stored palettes, such as 256 gray levels and several color palettes that have useful variation in saturation and brightness. Importantly, one can define a new palette and save it. The colors are defined through use of the Macintosh RGB or HSV color wheel or through several other standard color definition systems. For example, as will be discussed below, we could design stimuli to be isoluminant according to psychophysical criteria and save the settings for later creation of stimuli. We found that the palette with 256 gray scale levels was of tremendous help in generating many demonstrations. We even found that we could use the Apple Color Picker wheel evoked by the control panel to demonstrate variations in hue, saturation, and value to students. They could also get an appreciation of trichromatic color mixture, since they could declare RGB values and see the results. For example, entering equal $R$ and $G$ produced yellow, and equal amounts of $R, G$, and $B$ yielded white. This was an easy demonstration of the textbook's discussion of color.

\section{Demonstrations of Phenomena and Effects}

In the course of a 10-week quarter, an undergraduate class generated credible demonstrations of many perceptual effects. They scoured the journals and were able to duplicate many phenomena, and we generated some new illusions (to be presented elsewhere). Specifically, we produced versions of the effects in Appendix C. In gen- 
eral, they are more effective when viewed on the monitors than with the limited gray scale resolution of the Apple LaserWriter INT used for our figures.

Static images. One set of phenomena comprises the static brightness, contrast, and pattern effects presented in Figures 1-6. They were done with Pixel Paint Professional, using the gray scale palette. We used this program, because of its wide range of graphic tools. Figure 1A represents a variant of an illusory contour (Gerbino \& Kanizsa, 1987; Petry \& Meyer, 1987). A light-gray fill is seen in the center of the square. Concentric circles were drawn, and, using the program's selection square, we chose a command to lighten the area in the interior corners. The illusion then appears. Figure $1 \mathrm{~B}$ reproduces a diffuse illusory contour with a fuzzy glow (Minguizzi, 1987). We drew a standard Kanizsa triangle, and, using a "waterdrop" tool, we blurred the borders of the sectored disk to produce the effect. Figure $1 \mathrm{C}$ represents the Craik-Cornsweet-O'Brien illusion (Frisby, 1979). The right square looks lighter than the left, even though the outside edges are equal in gray scale. This can be checked by covering the central border with one's finger. It is an assimilation effect, generated by having equal gray levels on the outsides that sharply drop or increase at the center. Pixel Paint Professional enables one to fill a rectangle with a gradient chosen from a palette with the rate of change being linear, accelerating or decelerating, and we used this to duplicate the display in Frisby's book. No programming was needed. Figure 1D is an example of subjective transparency (see Kanizsa, 1979). Conditions for transparency depend on the lightness ratios of the four areas in the figure. We drew the two larger rectangles, and then, using a program-supplied transparency control, we superimposed a middle gray square over the two. We could thus easily duplicate most of the transparency phenomena in the literature. Figure 1E represents the change in appearance of the classic gray rectangle over a set of varying gray squares, except that the background is now a ramp (seen as continuous on a monitor). The display is more striking. We also animated it, using MacroMind Director, so that the circle moves. It seems as if the constant gray circle is moving under a light source and almost glows at points. It is a powerful and effective demonstration of brightness contrast.

Another set of effects is presented in Figure 2. The upper left corner presents the classic Hering grid that is used to demonstrate lateral inhibition and is explained as the function of retinal ganglion cell receptive fields (Cornsweet, 1970). It would be easy to change sizes, contrasts, and even colors in the display. Next to it is an example of van Tuijl's (1975) neon illusion. The central panel demonstrates a more recent topic of interest: shape through shading. Ramachandran (1990), among others, has produced displays in which appropriate gradients in a shape produce a strong 3-D effect. Although the actual gradient of a real object can of course be calculated mathematically, we found that by using the 256 gray scale levels and Pixel Paint Professional's gradient fills, we could produce excellent displays. Shadowing, with either sharp or diffuse edges, can also be added to enhance depth. In Figure 3, some of the various fill options are presented. Such gradient fill abilities are found in other programs as well (MacroMind Director for one).

The phenomena of texture segregation are of major importance to visual perception because they speak to preattentive processing, visual search, and spatial frequency analyses (Enns et al., 1990; Frisby, 1979; Julesz, 1981; Meyer \& Petry, 1987). In the lower right corner of Figure 2 , one example of a texture segregation is presented to compare the efficacy of processing conjunctions ( $\mathrm{L}$ vs. $\mathrm{T}$ ) and orientation (tilted T). One can use the tools in the programs that we selected to duplicate almost any texture display in the literature, except for ones based on spatial filtering. The displays can be passed to programs such as Director or Supercard for display as demos or for research.

Bars of varying contrast are presented in the lower corner of Figure 2. On faith, one must believe that the blank gap that is third from the right represents a bar at just-noticeable contrast on our monitors. This enables us to demonstrate both contrast threshold and the human contrast-sensitivity function (CSF; Cornsweet, 1970) to our students. By using the gray scale palette, we built a set of gratings of various contrasts and spatial frequencies. We were forced to use square waves, but we were able to smooth the edges somewhat. The displays were used as frames in MacroMind Director and presented to students according to the method of limits or constant stimuli. The plotted functions were comparable to those in the literature. Thus, a class in perception could actually see what contrast threshold and the CSF were actually about. It seemed to confer reality upon spatial frequency, acuity limits, contrast, low spatial frequency decline, and psychophysical technique. We could even produce a reasonable version of the Campbell and Robson CSF figure, in which spatial frequency and contrast were simultaneously varied (Cornsweet, 1970, p. 343), using Pixel Pro's gradient fills, gray palette, and smoothing functions. Unfortunately, it does not reproduce well on laser printers.

Another fascinating example of the role of spatial frequency analysis involves the "Abraham Lincoln effect" pictures of Harmon and Julesz (1973). By summing gray levels over a given block size, the face of Lincoln was masked until the picture was viewed at a sufficient distance to minimize the high-frequency edges of the blocks. This amusing effect is now used to disguise drug lords and others on the evening news. It is also found in most perception texts. To our delight, we found this to be a built-in function of Pixel Pro. A mosaic command with variable pixel size blocks will produce the effect. We first transformed some company-supplied clip art, such as an apple or fish. We then scanned the face of students, using MacVision, and transformed them on line and in real time. An example of one of the authors is found in Figure 4 (Figure 5B shows the original face). The phenomenon provides an excellent classroom demonstration; students can change block size in real time and appreciate spatial 


\section{Brightness and Contrast Effects}
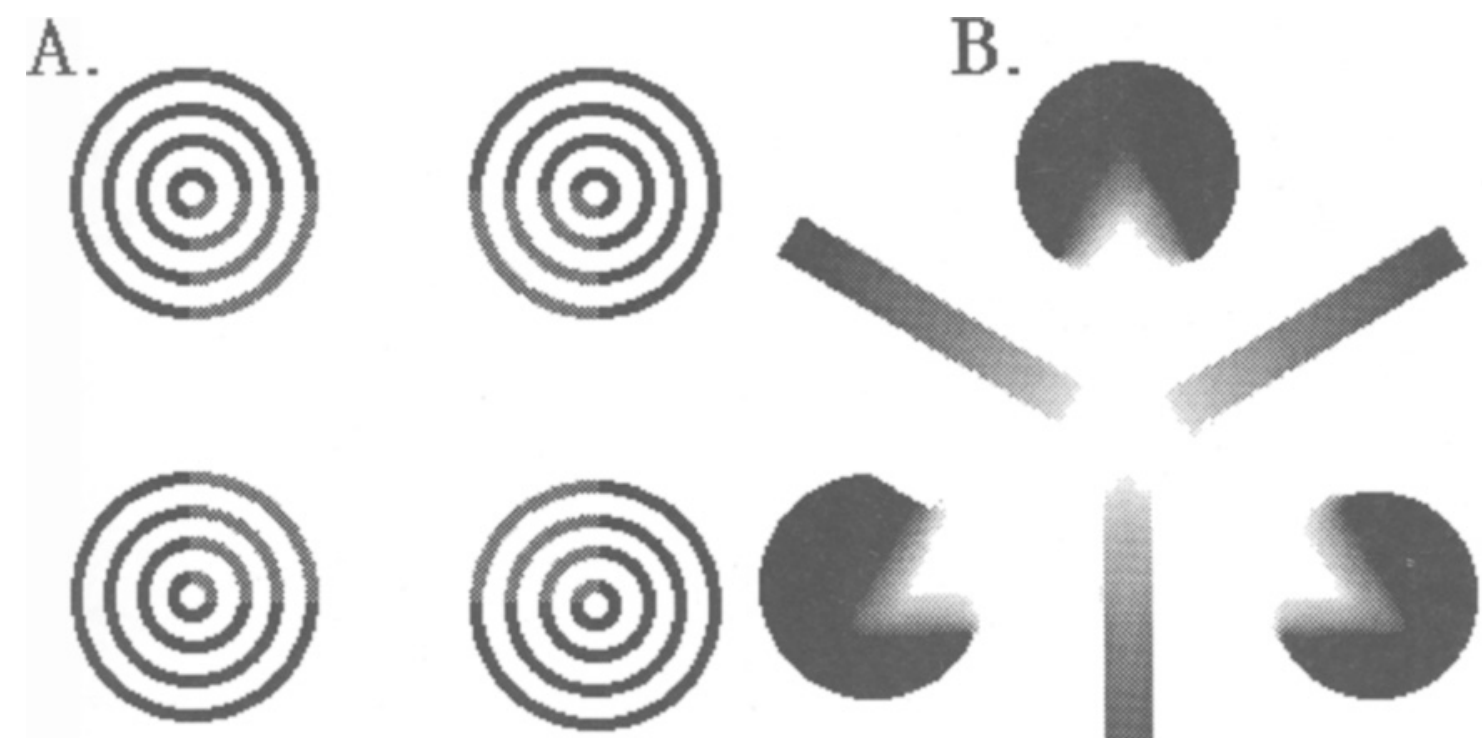

C.
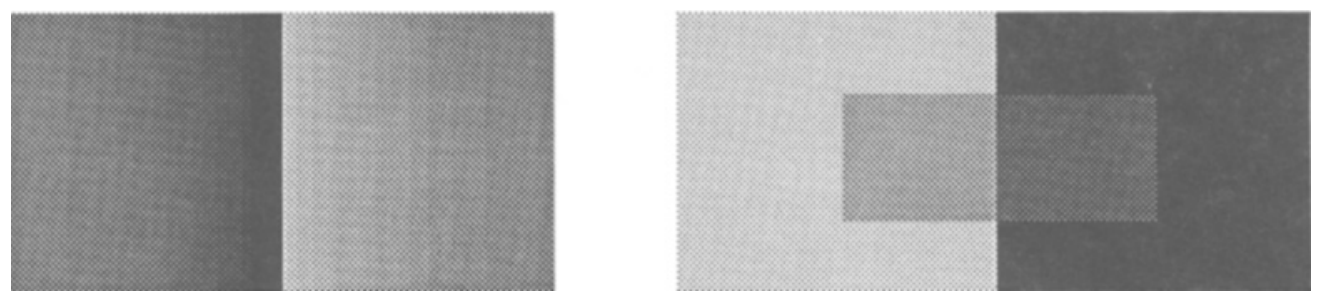

D.

E.

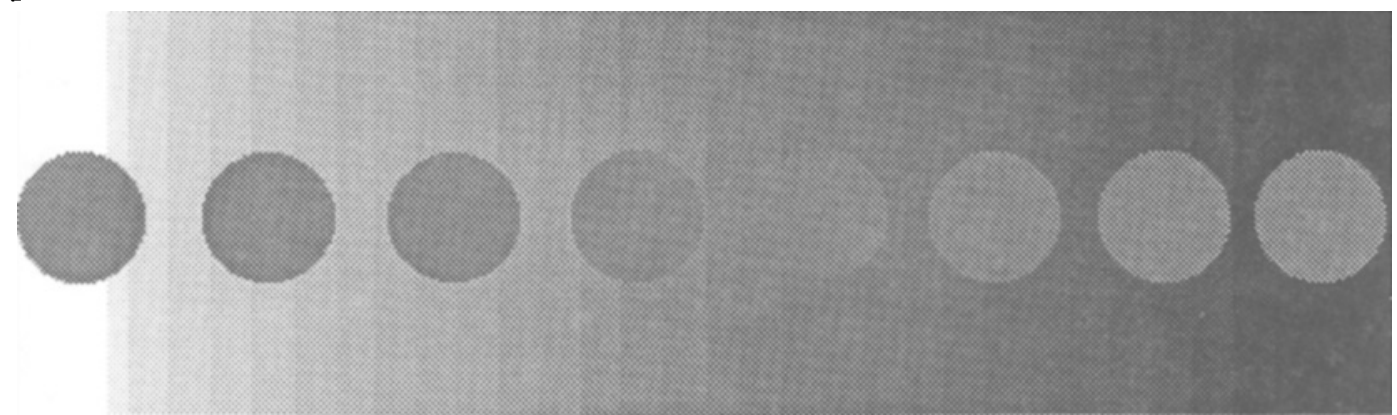

Figure 1. Brightness and contrast effects. (A) Gray filled illusory contour. (B) Diffuse illusory contour. (C) Craik-Cornsweet-O'Brien illusion. (D) Subjective transparency. (E) Simultaneous brightness contrast. 


\section{Hering Grid Neon lllusion}
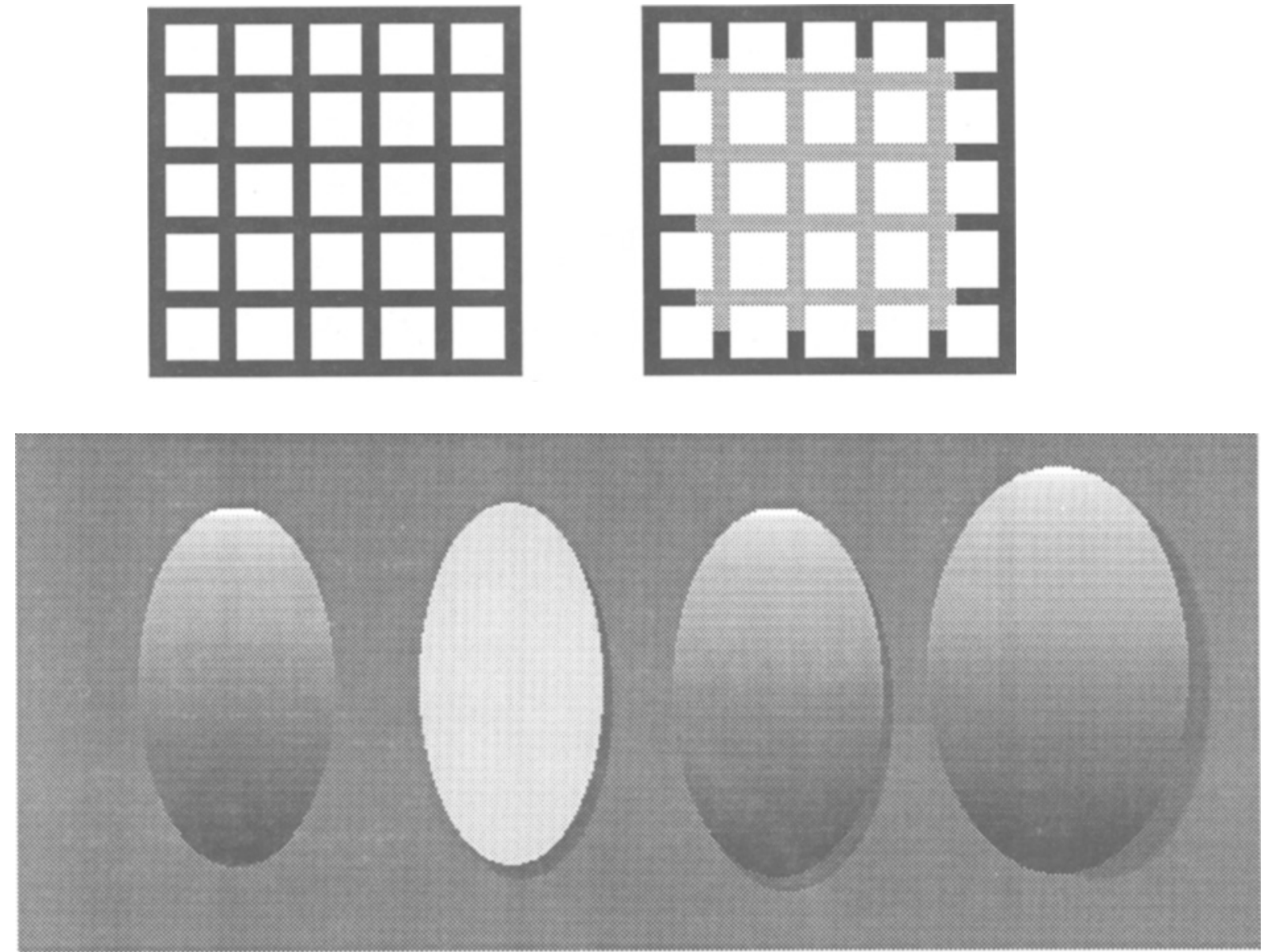

\section{Varieties of Shading and Shadow}

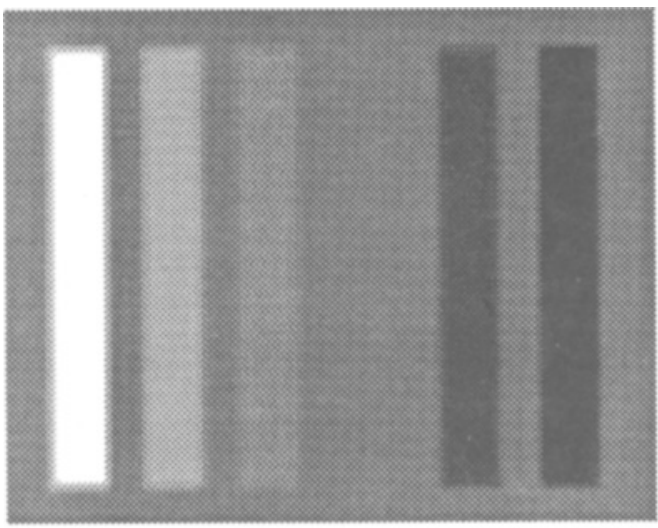

Contrast

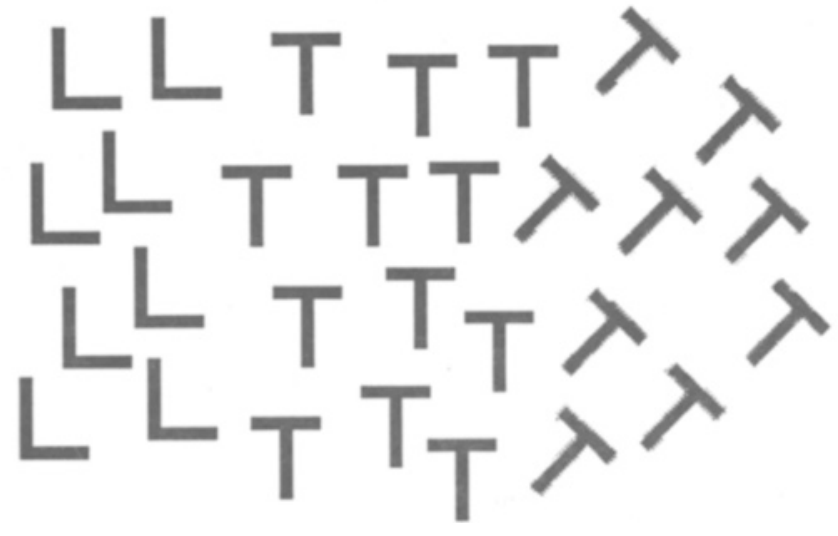

Texture Segreation

Figure 2. Starting from top: Hering grid and illusory gray dots; neon illusion; shape through shading and shadowing; levels of contrast available through gray scale palette; texture segregation. 


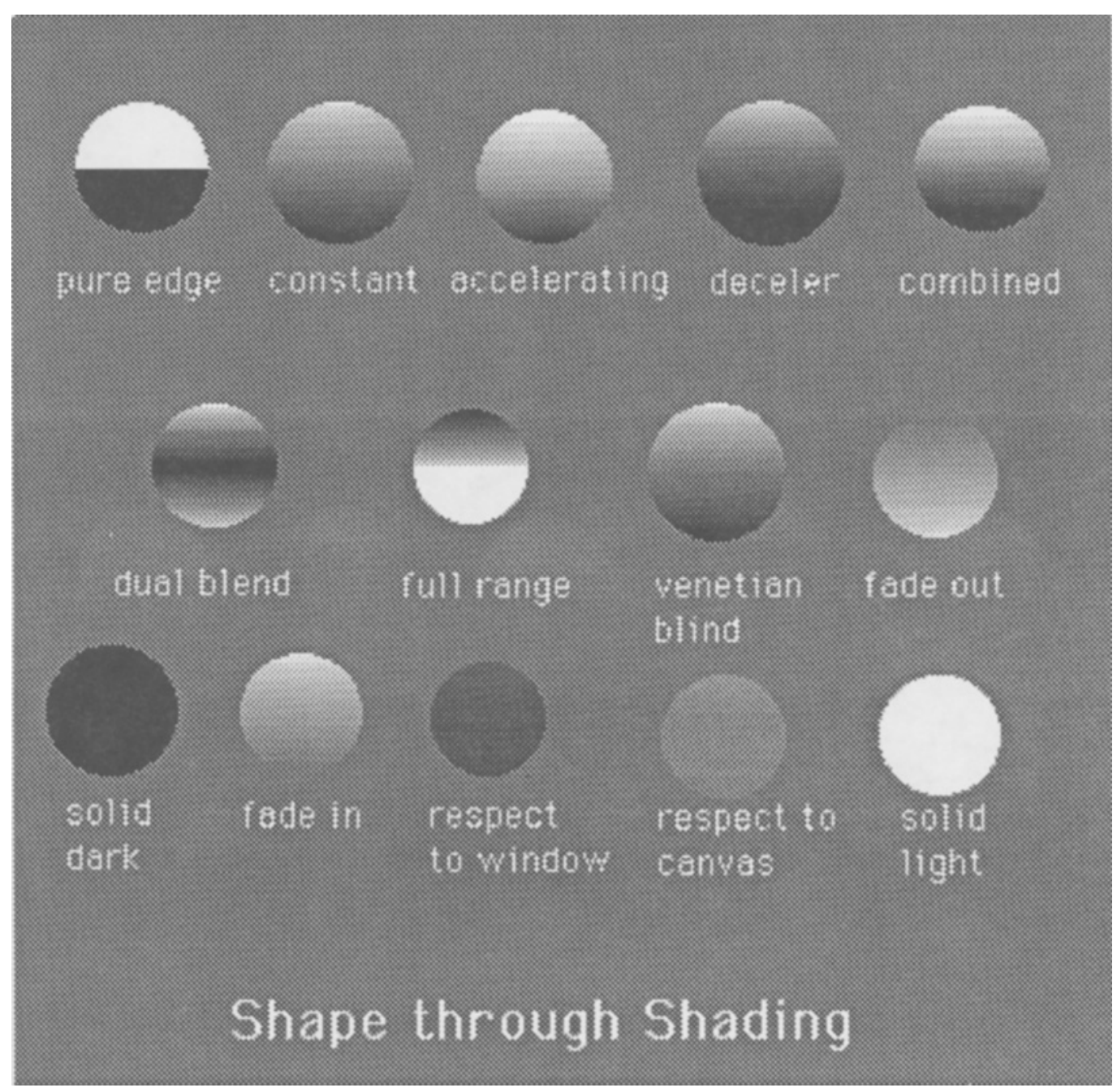

Figure 3. Circles filled with various gradient options by Pixel Paint Professional. Note that some of them produce powerful shape through shading.

filtering in an interactive manner, without using specialpurpose software.

Faces can be used in other visual phenomena. The literature of lateral preference and hemispherical asymmetry speaks to lack of symmetry of the sides of a human face and to the differences in processing emotional information. Sackheim, Gur, and Saucy (1978) reported that emotions are expressed more intensely on the left side of the face. In Figure 5A, we present Dan Rocheleau constructed from the left side of his face and from the right side. This was done by selecting a side of his face (Figure 5B) and using a mirroring command in Pixel Paint. The effect is dramatic. It takes about $5 \mathrm{~min}$ to do this. Last, with the same basic face, we demonstrate the Margaret Thatcher illusion (Thompson, 1980). We selected the eyes and mouth and rotated them. The face was rotated or not, and then the images were combined.

These were demonstrations. However, conditions can be reasonably controlled with the built-in timing controls of the programs, and color and luminance can be manipulated with their palette commands. More sophisticated displays could be generated with 24-bit programs. The block digitization of Lincoln's face and our own could only be done in 24-bit mode. However, it did not take an extraordinary time to create any of the effects, and they are quite as reasonable as those seen in textbooks. Of course, the motion effects are not available in a text.

Another powerful effect and important part of any course in perception is the discussion of depth cues, stereopsis, and the role of retinal disparity (Julesz, 1981). It is not particularly difficult for students to construct their own random-dot stereograms. Programs do exist (Stork \& Rocca, 1989), but we could generate the stereograms quite easily with any of our graphics programs. The department possessed a Keystone 46B Visual Survey Telebinocular (a fancy prism stereoviewer; but mirrors will do). We mapped out dimensions of stereogram pairs from the stereograms supplied with the stereoscope. Using the pat- 


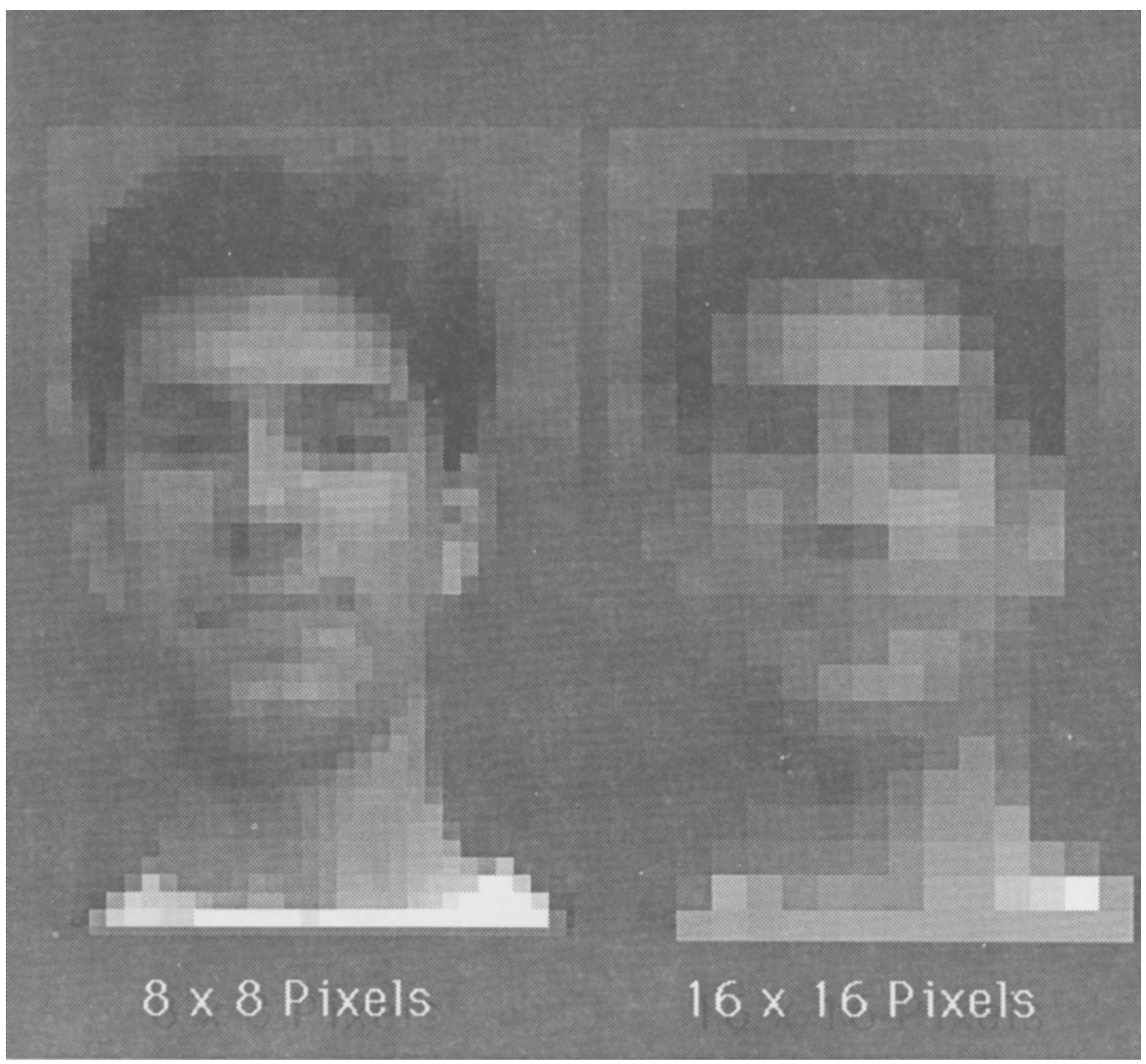

Figure 4. Application of Harmon and Julesz's (1973) filtering to a scanned face of the second author. Summation occurs over a block of $8 \times 8$ pixels or $16 \times 16$ pixels.

tern palette and filled-square primitive of almost all Macintosh graphics programs, one can define a grid and then fill it with black and white squares chosen at random (use a coin or random number table). Then one can select patches in the desired shape, give them an appropriate lateral shift, print both pairs, and have a stereogram (Figure 6.1-6.5). Students can explore the relations of the shift to disparity by altering the exact displacements used. The complexity of the stereogram depends on their creativity. We also found that the grid could be used to demonstrate properties of symmetry (Julesz, 1971) by mirror-imaging the grid as we did above with human faces. Also, the grid pairs from the stereograms (Figure 6.5) can be used as stimuli for random-dot apparent motion (Cavanagh \& Mather, 1989) if transferred to MacroMind Director.

Movement-based phenomena and presentation control. The phenomena discussed above are basically static; one can present them on a screen to students. It is obvious that modern perception entails presentation of sequences of stimuli and effects that involve motion. Several programs can be used to present sequences with some degree of stimulus control (Hypercard, Supercard), and several programs exist that have been designed for this purpose (Mindlab, MacLab). However, they have limited graphics abilities. We chose to use a powerful animation and presentation program: MacroMind Director 2.0. Thus students could work with one program that had many integrated 


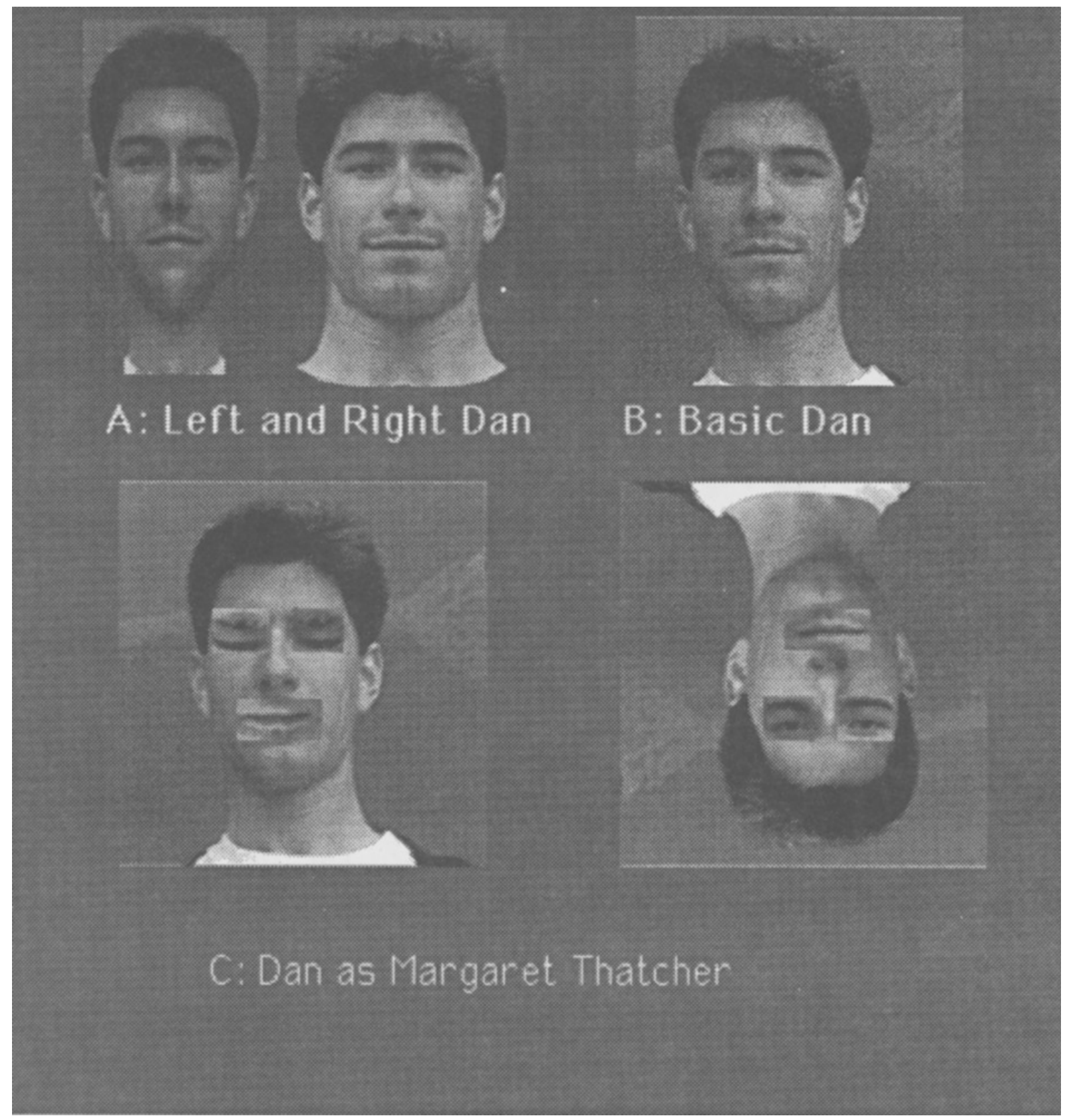

Figure 5. (A) Two full-faced composites of the second author, made by mirroring the left side of his face or the right side using Pixel Paint Professionsl. (B) The unaltered second author, as scanned by MacVision. (C) The second author subjected to the Margaret Thatcher illusion.

capabilities. A videotape of the demonstrations is available (see the author note at the beginning of this paper).

Director uses an animation framework. The user can create sets of objects (called cast members) by using a powerful set of 8- or 24-bit paint-like commands. The graphic set is very powerful and can stand alone for most problems. If more power is needed, cast members can be imported from almost any other graphics environment.
Most useful is the program's ability to systematically distort, rotate, resize, slant, alter the perspective of, smooth, lighten, or darken one cast member to create a series of objects to be used in an animation sequence. The objects can be strung along a set path to generate motions such as translations or rotations with correct control of timing and alignment. This is much easier than frame-by-frame creation of a large set of objects that are then fed into Hyper- 


\section{Random Dot Effects}

1.Create Grid
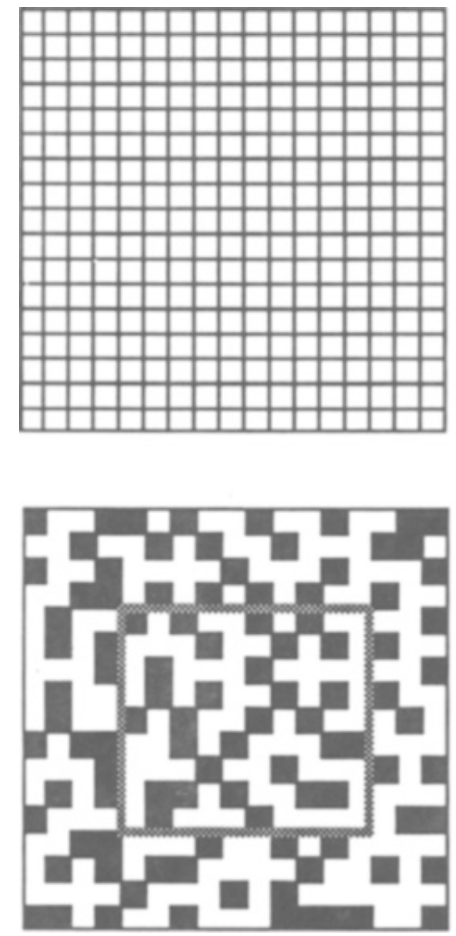

\section{Select Area}

2. Fill Grid
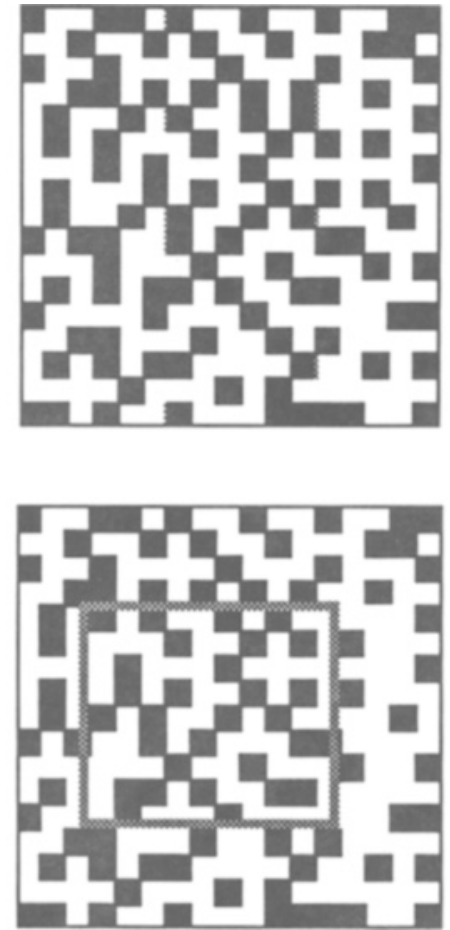

3. Mirror Sym.
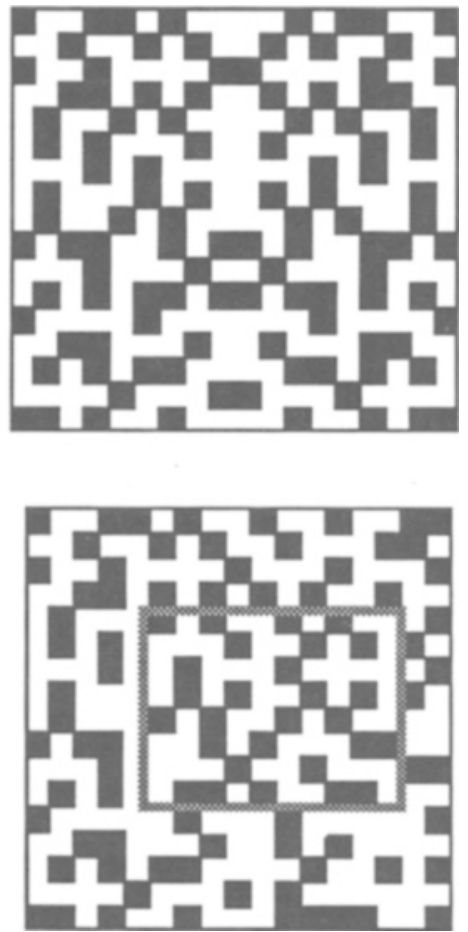

\section{Duplicate and Shift Areas} (Stereograms/Apparent Motion)

Figure 6. The generation of random-dot patterns using the pattern palettes of Pixel Paint Professional. Symmetry, stereograms, and apparent motion displays can be produced.

card or Supercard, with displacements and time designated on a frame-by-frame basis. These abilities can be used not only to create animations but to arrange presentations.

An example is shown in Figure 7. The targets represent a series of targets to be rotated to produce the stereokinetic effect (Bressan \& Vallortigara, 1987; Musatti, 1924). The targets appear to be 3-D; it is an impressive display. Figure $7 \mathrm{~A}$ represents the cast members. They were drawn and then automatically rotated in increments under menu control (A16-A18). They appear on the stage (screen) as in Figure 7B. Control of the animation sequence is presented in Figure 7C, where each vertical division represents a frame or complete screen. The horizontal lines represent the cast members that appear. For example, Line 2 represents A16, A17, A18, and so forth, or the beginning of the rotation of the striped globe seen on the left of Figure 7B. Figure 7C also contains a real-time clock for timing control, as well as menus to control over- lap of stimuli with various Boolean operations. Figure 7D shows the control panel, which plays the animation like a VCR and has speed controls. Director also allows one to save a complete movie with transitions, captions, and so on.

It was quite easy to produce demonstrations with these abilities. For example, we created a set of red vertical and green horizontal gratings. We alternated them in the score window to induce the well-known orientation-contingent color aftereffect known as the McCollough effect (McCollough, 1965). The test pattern was a half vertical and half horizontal black and white grating, which then rotated. Students noted when the complementary colors faded. The tuning curve thus derived was comparable with that presented in the literature. Timing was controlled by the program's built-in functions. We could also easily generate test and adaptation patterns differing in spatial frequency and motion. A student honors project is using the color 


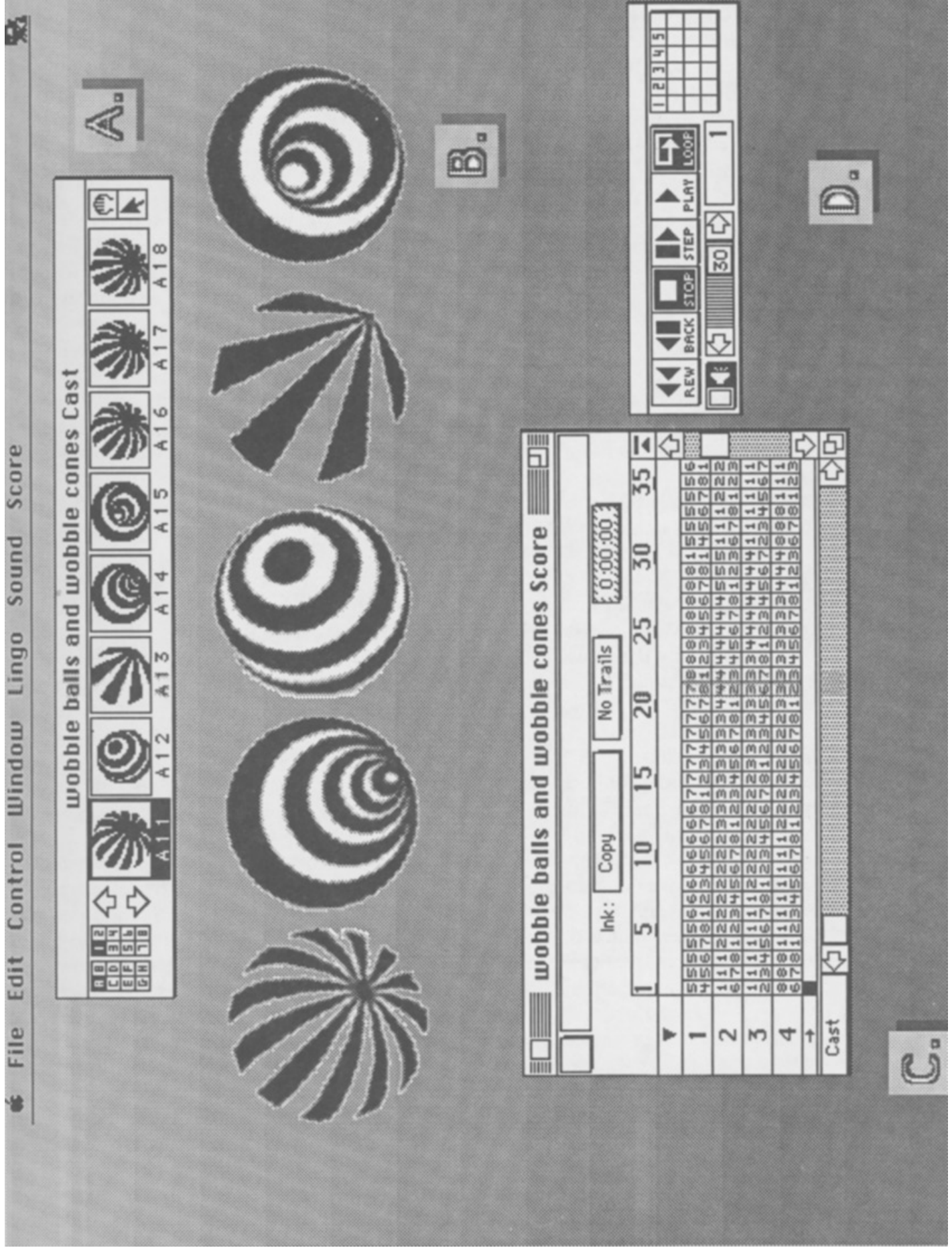

홀

른

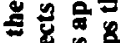

충응 는

볼

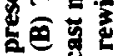

จ

结 콜

\&

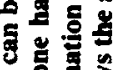

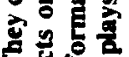

을

웅형

옹응

家客

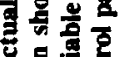

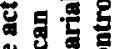

事定

렬

它

홍형

동 훙

氜氙夏

호을

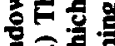

오올

ษ

蛋量

봉

造 务

它焉

兘它

응

형형

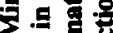

은

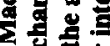

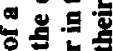

홍ㅎㅇ응

\&

협을형영

용요

巻要焉

$<$ 월

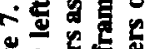

놀농농

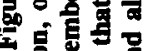

․ㅗ을 
palette to create a set of test stimuli in which the saturation of a set of complementary gratings is varied for more precise testing.

Similarly, we created a set of gratings varying in contrast and spatial frequency. They were presented in random orders (method of constant stimuli) or in ascending and descending sequences (method of constant stimuli) to produce quite reasonable contrast-sensitivity functions (Cornsweet, 1970). It would be difficult to do this in Hypercard. In the same vein, we animated the simultaneous contrast demonstration of Figure $1 \mathrm{E}$ for a striking display as previously mentioned.

The ability to present displays frame by frame allows us to produce apparent motion displays of some complexity, using objects or random dots. Visual persistence could be tested, and the aperture effect was easily generated. Although demonstrations of these already exist, we had students create them and try their own ideas without resorting to complex programming. Director is easy to use. A list of phenomena is presented in Appendix C. Figure 8 demonstrates how illusions of rigidity and nonrigidity can be generated (Meyer \& Dougherty, 1990). Basically, we could duplicate most of the effects found in a journal such as Perception (see, e.g., Braunstein \& Andersen, 1984), unless the phenomenon called for spatial filtering. It was easy to produce all the animated subjective contours in Petry and Meyer's (1987) book on illusory contours.

Even "cutting-edge" displays can be produced. One of the hottest perceptual techniques today is the use of isoluminance to separate the channels used by the visual system. Although this is controversial, it is thought that an isoluminant display based on color might channel information through the "P" or parvocellular channels (Cavanagh \& Mather, 1989; Livingstone \& Hubel, 1987; Ramachandran, 1990). Three-dimensional perceptions are altered, and motion phenomena may be weakened. With the palette controls in Pixel Paint or Director, we could produce reasonable isoluminant displays by using criteria such as minimally distinct border. Subjective contours would disappear, as has been reported several times. Livingstone and Hubel's (1987) displays were duplicated. The color settings with Director enabled us to duplicate Ramachandran's (1990) motion capture phenomenon, as presented in Figure 9.

If isoluminant and stationary blue squares are presented on a gray background, they will be captured by a moving set of black dots. In other words, the blue squares are dragged by the dots, even though the squares do not move. We duplicated this in the course of an afternoon's lab session. Obviously other such displays can be produced. Cavangh and Mather (1989, Figure 1) also discuss higher order motion stimuli defined by continuously changing textures. By filling the displays with textures rather than colors, we could switch between domains in minutes. If more care is taken, the colors can be quantified and timing controlled, so that they can be used in original research.
A last hot topic is structure from motion. Since the discovery of the kinetic depth effect, we have been aware that motion itself can determine form (Sumi, 1989; Wallach and O'Connell, 1953). Stimuli can be constructed so that a single frame is not recognizable as an object. However, a series of frames will clearly define the object and even give a strong sense of three-dimensionality. Random-dot patterns are sometimes used. As described previously, one could (Figure 6) place random-dot frames in alternation or in sequence and produce powerful movement effects of the target shape. Two-dimensional shapes are easily generated by the accretion and deletion of textures (Meyer \& Petry, 1987).

Ullman (1979) has demonstrated how 3-D form can be recovered from stimuli moving in depth. Compelling stereokinetic depth can be seen in random-dot patterns that would follow the surface of a sphere or cylinder. Each frame, however, is unrecognizable. Most researchers seem to have produced such displays with original programming. We found that we could produce striking displays (videotape available from authors; see the author note) by using a combination of programs. Super 3-D is a 3-D modeling and animation program. Using a typical Macintosh interface, one can draw shapes and move them. This is interesting in and of itself. However, we generated compelling structure-from-motion displays by creating a 3-D object such as a chair or a sphere. We then stuck white dots on the object or even through its interior. The object and dots were next moved or rotated in one or more axes. The object was then deleted from the sequences, leaving just the dots. In static view, no 3-D shape was perceivedjust a patch of dots on a black background. When the dot sequence played, the sphere or chair sprang into view. It generated gasps of amazement. Two frames of the chair sequence are presented in Figure 10. In the top frame, the chair is highlighted in gray. In the bottom, the chair is still there, but it is rotating away with motion in the three axes.

More compelling variants were constructed. By importing the sequences of frames to Director, we gain fuller animation control. We superimposed the dot sequences over a background of constant random dots, so that in any given frame one could not even tell that a patch of dots was present. When the sequence played, the shape appeared segregated from the dot background. An even more powerful demonstration of our ability to recover form from motion was to have the background dots change randomly from frame to frame. The background appeared as a swirling snowstorm. Still, the sphere or chair was perceived. It made the case of the role of motion in depth or form processing in a manner far more compelling than any written description could. For research purposes, it would not be difficult to decrease the number of dots in the objects to test thresholds or a variety of other measures. Programming the display would be difficult in the limited amount of time that we had in the course. Even if we had programmed the display, would one want to reprogram it just to alter some characteristics? 


\section{A. Animation Sequence:}
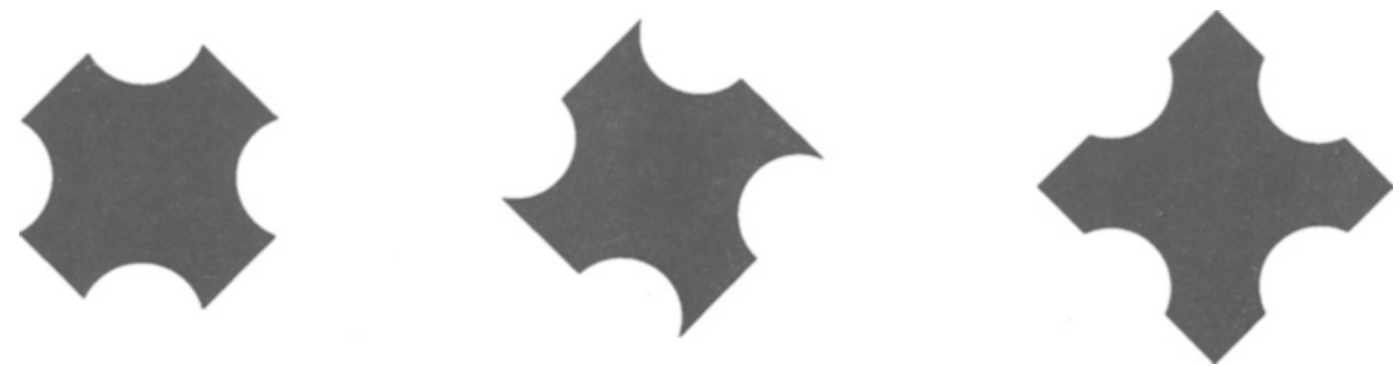

\section{B. Subjective Figure - Ground Organization \& Rigidity}

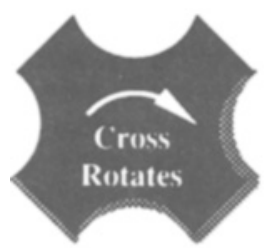

Nonrigid, Oozing Black Rubber Cross

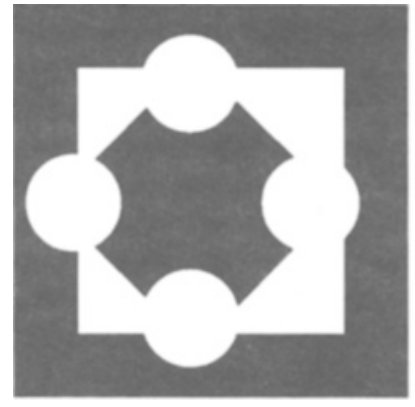

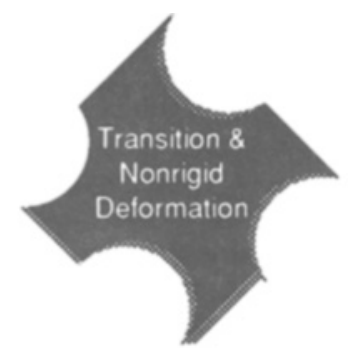

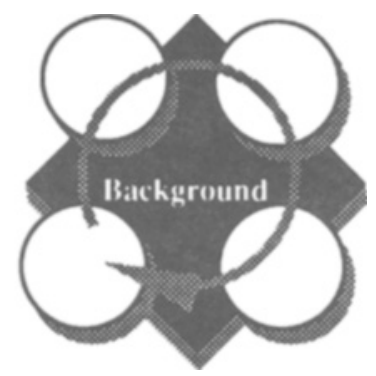

Diamond with Circles Rotating Above
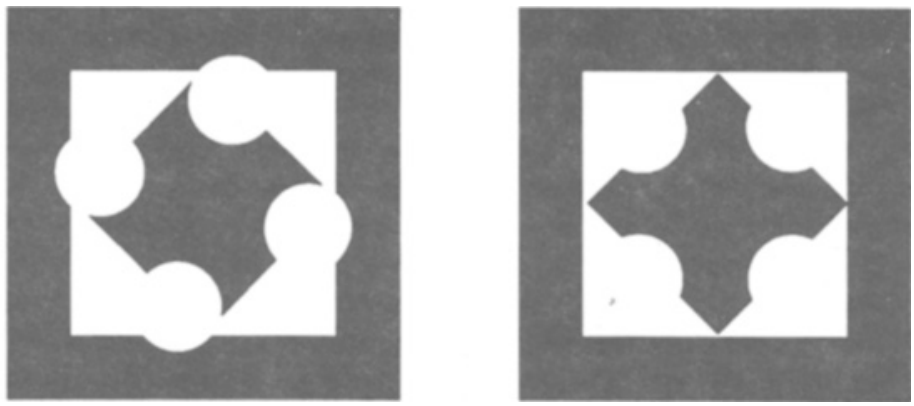

\section{Illusory Circles Maintain Rigidity}

Figure 8. A set of animation frames, which produces an illusion of ambiguous rigidity and nonrigidity (Meyer \& Dougherty, in press). 


\section{Capture of Chromatic Boundaries}
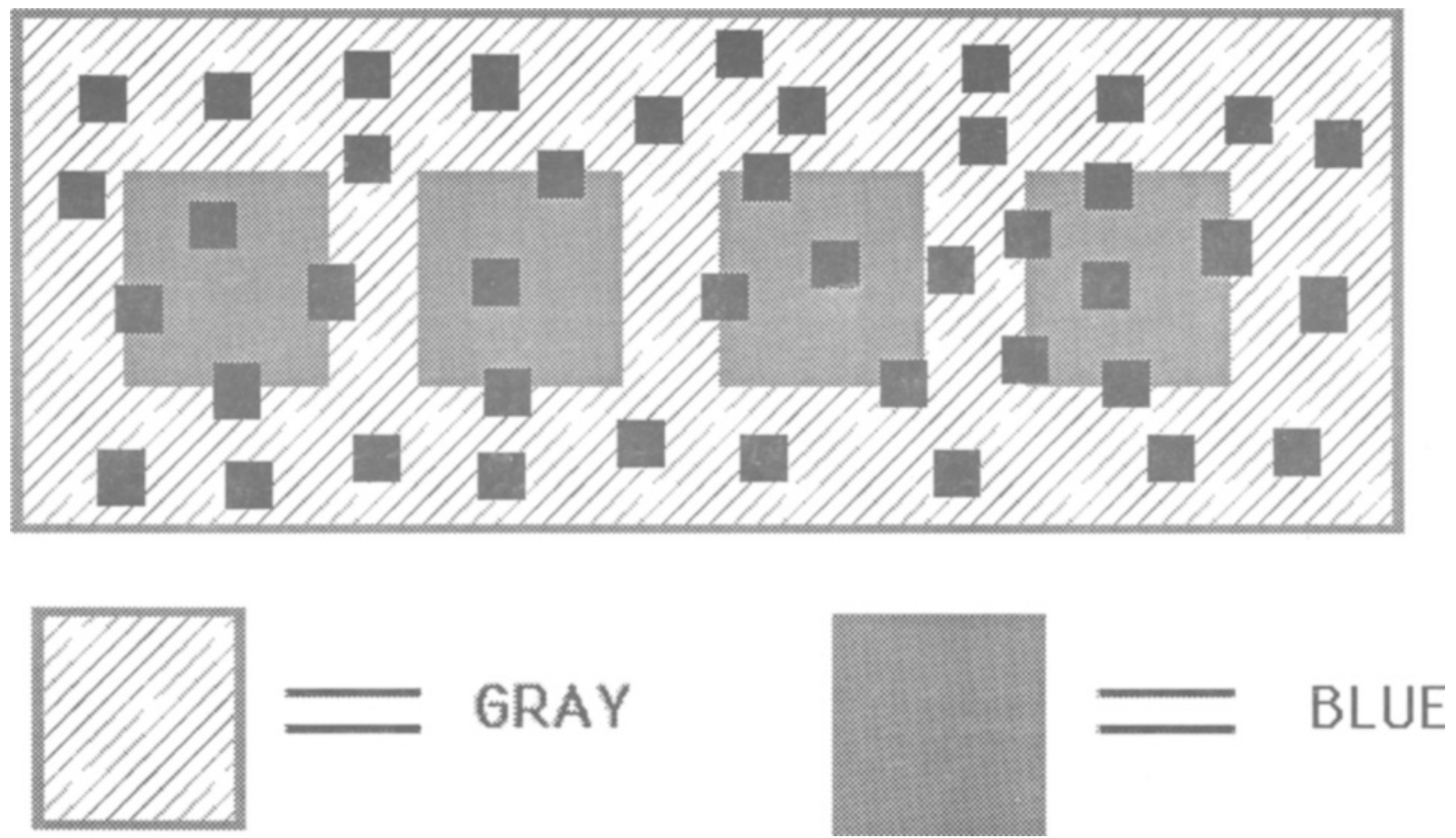

Figure 9. Motion capture of isoluminant blue squares on a gray background. As the black dots move across the screen, the blue squares seem to move with them (Ramachandran, 1990).

\section{Problems and Costs}

The Macintoshes that we used were fairly expensive ( $\$ 6,000$ each at time of purchase). We would not recommend attempting this work on machines with less than $8 \mathrm{MB}$ of memory. With less memory, software tended to crash. Also, to use Pixel Paint Professional, a 24-bit color board is required, which adds $\$ 800$ or more to the cost of the machine.

Programs are not cheap. Prices ranged from $\$ 400$ to $\$ 600$ per program. However, through contacting the companies directly, we found that educational discounts and lab packs bring prices below street prices. For example, we were able to purchase five copies of MacroMind Director 1.0 and get the 2.0 update for $\$ 1,000$.

Also, the constant upgrade cycle is a problem. Staying with an old version has the risk of that version's not being able to communicate with newer programs. It is also the case that some older versions will not run under new versions of the operating system.

Multifinder, 32 Bit Quickdraw, and the 24-bit color board did not get along, and crashes were not rare. Director did not like Multifinder, and many other programs were prone to be bizarre under 32 Bit Quickdraw. Sometimes, we had to restart without it if we wanted to use other programs. Having two programs such as Canvas, Director, and Pixel Paint open at the same time was a sure path to disaster; the memory loads were too much. Some of the programs were buggy too. Features did not work. Some programs would reach out and color the desk top or draw windows that would not go away. It was better not to try to communicate from program to program. Since programs can open each other's files, it is better to generate and save a display, quit, and then get the display with the other program.

Timing was another problem. The programs are not set up to be tachistoscopes or to generate random stimuluspresentation sequences. They do not lend themselves easily to preprogrammed psychophysical experiments. Sometimes, results must be copied by hand or one must resort to old-fashioned methods of stimulus ordering. If we wanted to do a masking study with 1,000 trials, we might use a different program. However, we could still generate sophisticated stimuli and feed them to other programs that have gray scale capacity, like Supercard, or that use resources that allow color to be used with Hypercard, like MacLaboratory's Color Card. We await the all-purpose 24-bit tachistoscope, animation, data storage, and data analysis program. Maybe it will also write the article. 


\section{Structure From Motion:}

\section{Super 3-D ${ }^{\mathrm{MM}}$ to MacroMind Director ${ }^{\mathrm{TM}}$}
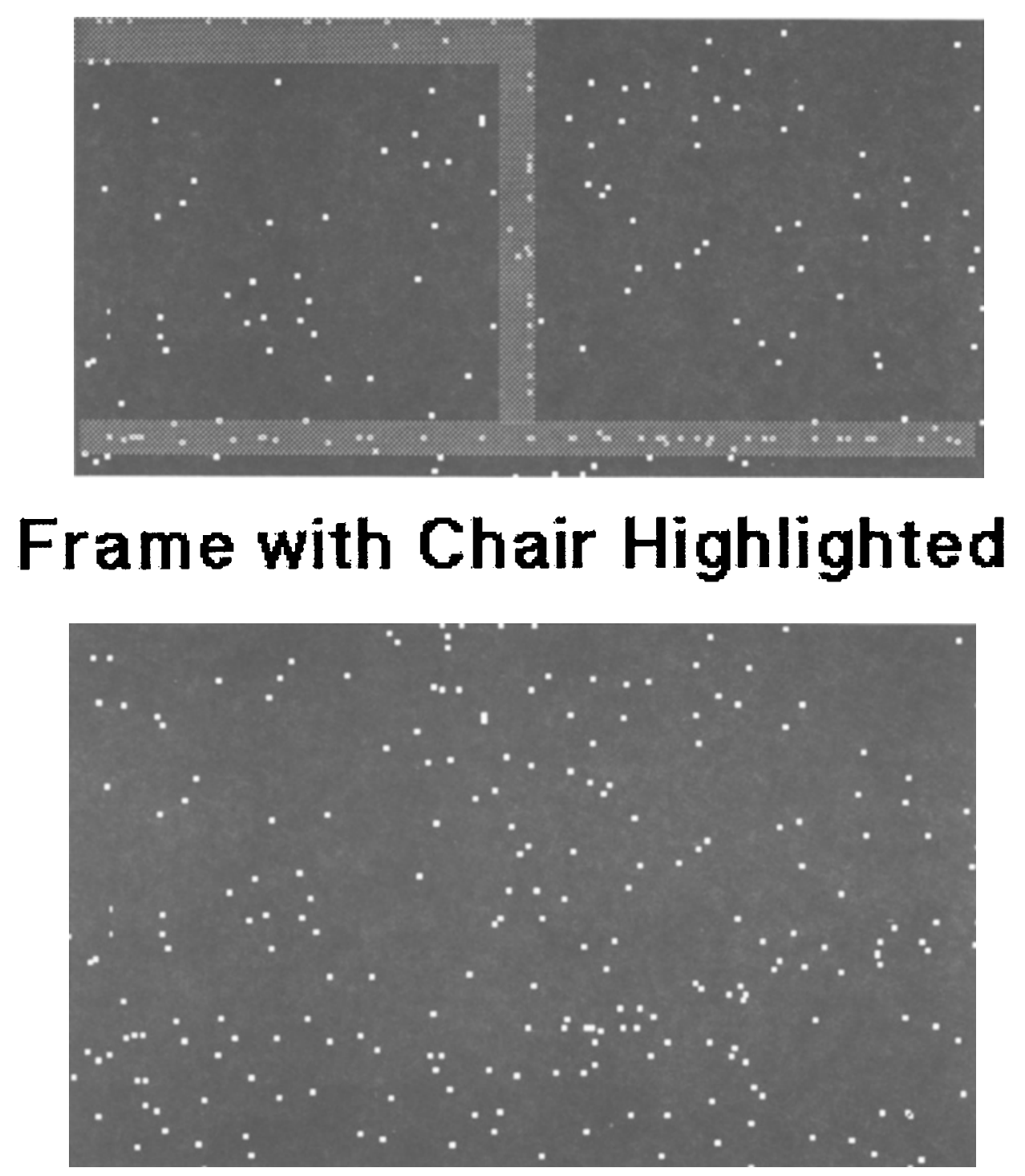

\section{Frame without Highlighting}

Figure 10. Structure from motion: When viewed, a chair composed of white dots is seen to be rotating in a field of random white dots. In the top panel, the approximate location of the chair is highlighted in gray. In the second frame, the chair is rotating away and is not visible in this static presentation. It is clearly seen in the animation. It was created with Super 3-D and MacroMind Director, as described in the text. 
We also did not find an easy way for students to produce true sine-wave gratings. It is not a standard primitive for graphics programs, and our goal was to avoid programming. None of the programs that we used would accept an equation for control of pixel characteristics. Special purpose software would be necessary for anyone who would do that.

\section{Conclusion}

We found that undergraduate students who had some experience on the Macintosh were capable of producing a wide variety of perceptual phenomena by using commercially available software. The students were encouraged to manipulate the figures, which they could do easily. The utility of this experience in teaching is self-evident. It is actually an enjoyable lab experience. Although some of our demonstrations lacked parametric variation and strict psychophysical measurements, we were able to make our pedagogical points. In one afternoon, students could produce displays described in the journals. More precise control is available in the programs themselves and through the use of other programs such as Hypercard or Supercard. In summary, the lab appears to be a pedagogical success, because it enables nonprogrammers to produce sophisticated and currently studied perceptual phenomena.

\section{REFERENCES}

Anstis, S., \& PARAdiso, M. (1989). Programs for visual psychophysics on the Amiga: A tutorial. Behavior Research Methods, Instruments, \& Computers, 21, 548-563.

Bressan, P., \& Vallortigara, G. (1987). Stereokinesis with moving visual phantoms. Perception, 16, 73-78.

Braunstein, M. L., \& ANDersen, G. J. (1984). A counterexample to the rigidity assumption in the visual perception of structure from motion. Perception, 13, 213-217.

Cavanagh, P., Mather, G. (1989). Motion: The long and short of it. Spatial Vision, 4, 103-129.

ChUTE, D. L., DANIEL, R. S. (1988). MacLaboratory for psychology - laboratory manual. New York: McGraw-Hill.

Cornsweet, T. (1970). Visual perception. New York: Academic Press.

Dougherty, T. J. (1990). Contour: A hypermedia environment for teaching about subjective contours and other visual illusions. Behavior Research Methods, Instruments, \& Computers, 22, 223-227.

EnNs, J. T., Ochs, E. P., \& Rensink, R. A. (1990). VSearch: Macintosh software for experiments in visual search. Behavior Research Methods, Instruments, \& Computers, 22, 118-122.

FrisBy, J, P. (1979). Seeing. Oxford, U.K.: Oxford University Press.

Gerbino, W, , Kanizsa, G. (1987). Can we see constructs? In S. Petry \& G. E. Meyer (Eds.), The perception of illusory contours (pp. 246 . 252). New York: Springer.

HARMON, L. D., JULESZ, B. (1973). Masking in visual recognition: Effects of dimensional filtered noise. Science, 180, 1194-1197.

Julesz, B. (1971). Foundations of cyclopean perception. Chicago: University of Chicago Press.

JULESz, B. (1981). Figure and ground perception in briefly presented isodipole textures. In M. Kubovy \& J. R. Pomerantz (Eds.), Perceptual organization (pp. 27-54). Hillsdale, NJ: Erlbaum.

KANizsA, G. (1979). Organization in vision: Essays on gestalt perception. New York: Praeger.

Livingstone, M. S., * Hubel, D. H. (1987). Psychophysical evidence for separate channels for the perception of form, color, movement and depth. Journal of Neuroscience, 7, 3416-3468.

McCollough, C. (1965). Color adaptation of edge detectors in the human visual system. Science, 149, 1115-1116.

MEYER, G. E., \& DOUGHERTY, T. (in press). Ambiguous rigidity/fluidity and diamonds that ooze. Perception, 19, 491-496.
Meyer, G. E., \& Petry, G. E. (1987). Top-down and bottom-up: The illusory contour as a microcosm of issues in perception. In $\mathrm{S}$. Petry \& G. E. Meyer (Eds.), The perception of illusory contours (pp. 1-20). New York: Springer.

Milss, M. I., \& SCHIFF, W. (1988). The active eye stack [Computer program]. Hillsdale, NJ: Erlbaum.

Minguzzı, G. F. (1987). Anomalous figures and the tendency to continuation. In S. Petry \& G. E. Meyer (Eds.), The Perception of illusory contours (pp. 71-75). New York: Springer.

MusatTI, C. L. (1924). Sui fenomeni stereocinetici [Stereokinetic phenomena]. Archivio Italiano di Psicologia, 3, 105-120.

Petry, S., Meyer, G. E. (Eds.). (1987). The perception of illusory contours. New York: Springer.

Ramachandran, V. S. (1990). Visual perception in people and machines. In A. Blake \& T. Troscianko (Eds.), AI and the eye. New York: Wiley.

Rieber, L. P., Boyce, M. J., \& Assad, C. (1990). The effects of computer animation on adult learning and retrieval tasks. Journal of Computer-Based Instruction, 17, 46-52.

SACKhEIM, H. A., GUR, R. C., \& SAUCY, M. (1978). Emotions are expressed more intensely on the left side of the face. Science, 202, 434-436.

STORK, D. G., RocCA, C. (1989). Software for generating autorandom-dot stereograms. Behavior Research Methods, Instruments, \& Computers, 21, 525-534.

Sumi, S. (1989). Kinetic contours in rotating objects. Perception, 18, 293-302.

Thompson, P. (1980). Margaret Thatcher: A new illusion. Perception, 9, 483-484.

Ullman, S. (1979). The interpretation of visual motion. Cambridge, MA: MIT Press.

vaN TuIJ, H. F. J. M. (1975). A new visual illusion: Neonlike color spreading and complementary color induction between subjective contours. Acta Psychologia, 39, 441-445.

Wallach, H., \& O'CONNEll, D. N. (1953). "The kinetic depth effect." Journal of Experimental Psychology, 45, 205-217.

WENDEROTH, P. (1990). Software-based visual psychophysics using the Commodore Amiga with Deluxe Paint III. Behavior Research Methods, Instruments, \& Computers, 22, 383-388.

\section{APPENDIX A}

Computer Equipment Used in Visual Research as Described in Selected Journals for 1989

Perception

Adage RDS3000

Amiga 1000

Apple II

Apple II+

Applesoft BASIC with monitor

CAI Alpha Computer, CED 502 Interface, and Hewlett-

Packard display

Cambridge Electronic Design lab computer with Pluto Megares graphics

Computer control with Hewlett-Packard display controller

Genisco 3000 with Conrac monitor

Grinnell GMR-27 image processor

IBM AT

IBM PC AT with Conrac Video Display

IMI 455 vector graphics processor

Microcomputer

Microconsultant INTELLECT image processor

PDP-11/23 with Barco, Peritek VCG-color graphics

interface

PDP-11/23 with Innisfree Picasso image generator

PDP-11/40 with Tektronix display

PDP-11/60

PDP-11/73 with Tektronix display 
Pluto II with Corvus concept

Sun $3 / 160$

\section{Perception \& Psychophysics}

Acorn-BBC microcomputer with VELEC VS display Amiga 1000

Apple IIe

Apple IIe with Taxan monitor

Commodore 64

Computer driven

Grinnell GMR and 270 Image Processing System

Hewlett-Packard display a900 with Hewlett-Packard display

IBM PC clone with NEC display

IBM XT

IBM XT with Sigma Designs Dazzler I and Enhancer cards

LSI-11/23 and Grinnell GMR-274 frame buffer

LSI-11/73, Image Tech Model AP-512, and Barco

Mac Plus

Masccomp

Olivetti M-28 PC clone

PDP-11 with Tektronix display

PDP-11/23 with Innnisfree Picasso image generator

PDP-11/73 with Hewlett-Packard display (twice)

RT 11 with Panasonic Matrox

Symbolics 3600 LISP machine with Tektronix display

Tandy 1000

Terak 8510

Vectrix Model VX384 color graphics computer with Electrohome RGB

Spatial Vision (1988-1989)

Apple II +

Atari 1040 STF

Commodore 64 (twice)

Computer controlled

Corvus Concept with Pluto II graphics display

CRT

Grinnell Graphics and Conrac 5411 monitor

Lab computer

LISP machine with Tektronix display

Mac Plus

NEC PC-9801 I Iwatsu SS-6200

PC-Vision Frame Grabber

Stimulus generated by computer

Sun 3

Sun $3 / 50$

Z-80

\section{Vision Research}

8086 with CRT

Adage Frame buffer with Tektronix display

Amiga

Amiga 1000

Apple II and LED

CAI Alpha LSI with Sigma Electronic QVEC 2150

Commodore 128 with Tektronix display

Commodore 2001

Computer and CRT

Computer microprocessor

Computer with Hewlett-Packard display

Conventional display
Corvus Concept with Pluto II graphics display

Cromemco Z-2D

EPROMs with Tektronix display

Gould DeAnza IP8500 image processor, PDP-11/34 and

Phillips monitor

Graphics controller and monitor

Grinnell GMR-270 image processor

Hardware electronics

Heathkit ET-3400 microprocessor and Tektronix display

Hewlett-Packard 9836 computer with Hewlett-Packard display

Hewlett-Packard display and 1345 A vector oscilloscope

IBM AT with Revolution No. 9 graphics board

Lab computer and Joyce electronics display

LSI-11/23 with Grinnell GMR-274 frame buffer

LSI-11/23 with Joyce display

LSI-11/73

MicroVAX with Cromemco Z2D

NCR Tower, Cromemco Z80, and Joyce display

PC clone and Revolution graphics card

PDP-11 with Tektronix display

PDP-11/10 with Sigma QVEC

PDP-11/34A with Joyce display (twice)

PDP-11/73 with Joyce display

PDP-11/73 with Tektronix display

Sun $3 / 160 \mathrm{M}$

Symbolics 3670

VAX-11/750 to Adage RDS-3000 with Conrac RGB monitor

Note-The descriptions of the equipment were often ambiguous.

\section{APPENDIX B \\ Hardware and Software Used in Producing Demonstrations}

\section{Hardware}

Macintosh II: $8 \mathrm{MB}, 80-\mathrm{MB}$ hard disk, RasterOps Color Board 264 (24-bit color)

Macintosh IIx: 8 MB, 80-MB hard disk, RasterOps Color Board 264 (24-bit color)

Macintosh IIcx: $8 \mathrm{MB}, 80-\mathrm{MB}$ hard disk, Apple 8-bit video board (24-bit color)

Apple 13-in. RGB monitors

\section{Software}

Canvas 2.1 (Deneba Software) 8- or 24-bit draw and paint program

MacroMind Director 1.01 and 2.0 (MacroMind, Inc.): 8or 24-bit color animation program

MacVision 2.0 software and hardware for scanning images with video camera

Pixel Paint Professional 1.0 (Pixel Resources, Inc.) 24-bit paint program; requires a 24-bit color card

Super 3D (Silicon Beach Software) three-dimensional modeler and animator

\section{APPENDIX C \\ Phenomena and Effects Produced}

Animated subjective contours

Apparent motion

Aperture problem demonstrations 
Asymmetry of human faces

Brightness contrast (both stationary and animated)

Color wheel on control panel (color space, additive mixture, saturation)

Contrast assimilation

Contrast threshold measurement / CSF Measurement

Craik-Cornsweet-O'Brien illusion

Flicker fusion

Grating induction

Illusory contours

Isoluminance effects in motion, subjective contours, stereograms

Kinetic depth effect

Kinetic occlusion (accretion and deletion of texture)
Lincoln effect (separation of high and low spatial frequencies)

Margaret Thatcher illusion (of our faces)

McCollough effect-orientation, width, and motion

Neon illusion (stationary and animated)

Ramachandran texture and motion capture

Rigidity and nonrigidity illusions

Shape through shading

Sape through shadowing

Stereograms

Stereokinetic effect

Structure through motion (2-D and 3-D)

Texture segregation / popout

Transparency effects 